\title{
Even chromosomes have their weaknesses
}

The breaking and rejoining of different chromosomes can lead to serious medical conditions, but the cause of these translocations was thought to be largely random. It now emerges that sequence variation is probably responsible for the fracture-prone sites in our DNA.

Translocations are among the most frequent genetic aberration in humans - in fact, many of us carry them around without any noticeable effect on health. Because translocations occur sporadically in so many individuals, the molecular mechanism by which they arise has been difficult to pinpoint. Kato and colleagues have now concentrated on a recurrent translocation between human chromosomes 11 and 22; they noticed that many unrelated translocations occurred within palindromic AT-rich repeats (PATRRs).

The authors then took a closer look at the palindrome on chromosome 11 (PATRR11). In most normal individuals the palindrome is about $450 \mathrm{bp}$; however, other shorter variants are also present in the healthy population, which probably arise by deletions within the 450-bp allele. But are these size variants functionally important? To find out, the authors looked to see how frequently translocations occurred de novo in sperm that carried various combinations of the PATRR11 alleles. What they found was a startling variation of three orders of magnitude in the frequency of translocation, depending on the repeat size - from 1 in $10^{4}$ in the homozygote for the longest PATRR11 variant to 1 in $10^{7}$ in a heterozygote for shorter variants.

This is the first time that sequence variation has been found to underlie human translocations. The fact that PATRR-like sequences have been found at the breakpoints of translocations between other chromosomes reinforces the causal role of palindromes in these aberrations.

Tanita Casci

ORIGINAL RESEARCH PAPER Kato, T. et al. Genetic variation affects de novo translocation frequency. Science 311, 971 (2006) FURTHER READING Emanuel, B. S. \& Shaikh, T. H. Segmental duplications: an 'expanding' role in genomic instability and disease. Nature Rev. Genet. 2, 791-800 (2001) |van Gent, D. C. et al. Chromosomal stability and the DNA double-stranded break connection. Nature Rev. Genet. 2, 196-206 (2001)|Feuk, L. et al. Structural variation in the human genome. Nature Rev. Genet. 7, 85-97 (2006)

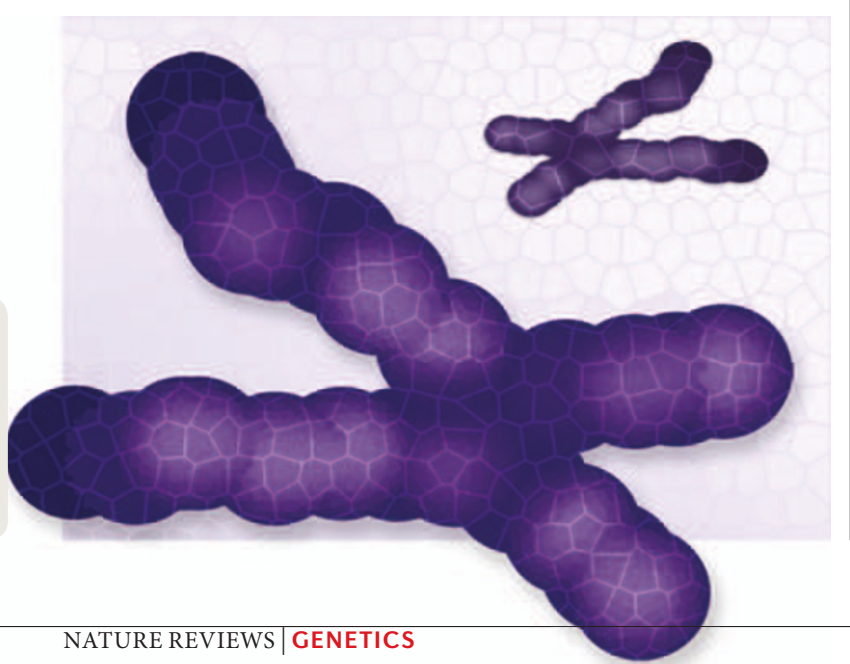

\section{CONTROLS OVER PLANT GENETIC RESOURCES -} A DOUBLE-EDGED SWORD

In industrialized countries, the proliferation of intellectual property rights (IPRs) that relate to biotechnologies, genes and plants has been dubbed an 'anti-commons' tragedy. Their extension to developing countries presents an even bigger concern, as the IPR models of the industrialized world might not cater for the needs of developing nations. Pressures to adopt IPRs arise primarily from trade instruments, rather than from the desire to support innovation in these countries. Private ownership of genetic resources also conflicts with widely held traditions in farming communities that 'seeds' should be freely shared.

As early as the 1980 s, worries about the concentration of power in the seed and pharmaceutical sectors were linked to the control of genetic resources. This resulted in these resources being brought under state sovereignty by the Convention on Biological Diversity (1992), allowing countries to regulate access to these genetic resources within their borders and negotiate a share of the benefits that arise from their use. It also stimulated the recognition of the rights of farmers and traditional healers, who developed and now maintain these resources within these countries.

A dilemma is now arising as countries start to develop and implement legislation on access and benefit sharing. These laws seem to be contributing to an anti-commons situation instead of reversing it; as stakeholders can veto access, transaction costs are skyrocketing, and laws could lead to preferential access by large multinational companies, which can promise the highest benefits. Groups that oppose the legal enclosure of genetic materials through IPRs have, paradoxically, promoted the development of mechanisms that keep even more materials out of the public domain. So far, this has led to a decline in exchange, while the benefits for farmers have been minimal.

The International Treaty on Plant Genetic Resources for Food and Agriculture (2004) attempts to address some of these concerns. Its multilateral system facilitates access and benefit sharing, reducing transaction costs and regaining some aspects of common access and use. A major task at the first session of its governing body in June 2006 will be to design rules for implementation that create significant benefits, while supporting the conservation and sustainable use of genetic resources, as well as farmers' rights.

In addition, strategies from the patent system that keep technologies available to farmers could be adapted and built into biodiversity laws to suit the exchange of genetic resources. These could include broad humanitarian license systems (as pioneered by the Generation Challenge Programme), joint IPR strategies that are followed by public universities (as developed by the Public Intellectual Property Resource for Agriculture), and open-source strategies (as initiated by CAMBIA).

Seeking to maximize benefits for access to agricultural genetic resources by using either IPRs or access laws will not support equity among nations or improve the livelihoods of those in developing countries.

Niels Louwaars, Senior Scientist of Biopolicies, Centre for Genetic Resources, Wageningen University \& Research Centre, The Netherlands. Formerly a visiting scientist at the secretariat of the United Nations Food and Agriculture Organization Commission on Genetic Resources for Food and Agriculture. e-mail:niels.louwaars@wur.nl

FURTHER READING Esquinas-Alcázar, J. Protecting crop genetic diversity for food security: political, ethical and technical challenges. Nature Rev. Genet. 6, 946-953 (2005)

FURTHER INFORMATION

CAMBIA: www.cambia.org

Generation Challenge Programme: www.generationCP.org

Public Intellectual Property Resource for Agriculture: www.pipra.org 